\title{
DIURNAL INTRAOCULAR PRESSURE VARIATION IN LOW-TENSION GLAUCOMA
}

\author{
CLEMENCIA DE VIVERO, COLM O'BRIEN, LUMINA LANIGAN and ROGER HITCHINGS \\ London
}

\begin{abstract}
SUMMARY
$A$ retrospective analysis of diurnal variation in intraocular pressure (IOP) in 101 untreated low-tension glaucoma (LTG) patients was carried out to ascertain the role of IOP as a causative factor in the aetiology of optic nerve damage in LTG. The diagnosis of LTG was made only after IOP monitoring as an inpatient, which involved 2 hourly consecutive measurements by Goldmann applanation tonometry from 08:00 to 22:00 hours inclusive. The highest IOP during the diurnal curve was $17.4 \mathrm{mmHg}$ (SD 3.00) at 10:00 and the lowest value was $15.0 \mathrm{mmHg}$ (SD 2.7) at 22:00. Seventy-seven per cent of patients had a peak IOP value recorded between 08:00 and 12:00 hours inclusive. The mean peak IOP was $18.3 \mathrm{mmHg}$ (SD 2.6) and the mean trough was $13.1 \mathrm{mmHg}$ (SD 2.2). Thus the mean diurnal range in IOP of $5.2 \mathrm{mmHg}$ (SD 2.2) was similar to that reported by other workers in normals. Neither the diurnal pattern nor the range of IOP values seen in this study supports the view that abnormal IOP levels are a significant risk factor in the pathogenesis of optic nerve damage in all patients with LTG.
\end{abstract}

Diurnal variation in intraocular pressure (IOP) was initially described in 1898 by Sidler-Huguenin. ${ }^{1}$ Fifty years later Duke-Elder, using a Schiotz tonometer, confirmed that this variation rarely exceeded $5 \mathrm{mmHg}$ in the normal population. ${ }^{2}$ As IOP is a dynamic event, continuous monitoring is essential not only to determine the pattern of IOP distribution within the individual, but also to differentiate patients with high-pressure glaucoma from those with low-pressure glaucoma. Patients with primary open angle glaucoma (POAG) demonstrate greater lability in their IOP during the day ${ }^{3-6}$ and IOP is known to be both a cause and a magnitude-related risk factor in POAG. ${ }^{7.8}$ Its role in the pathogenesis of low-tension glaucoma (LTG) is still unclear. We therefore analysed the diurnal distribution and behaviour of IOP in 101 LTG patients, in an attempt to explore the role of IOP in LTG.

From: Glaucoma Unit, Moorfields Eye Hospital, London, UK.

Correspondence to: Mr R. A. Hitchings, FRCS, FRCOphth, Moorfields Eye Hospital, City Road, London ECIV 2PD, UK.

\section{SUBJECTS AND METHODS}

The patients were identified from a retrospective review of 235 case notes of patients seen in the LTG clinic at Moorfields Eye Hospital between January 1981 and June 1992. All 101 patients in the study fulfilled the selection criteria in Table I. One eye of each patient was randomly selected for inclusion in the study. Sixty-two women and 39 men were analysed with a mean age of 62.4 years (SD 10.4, range 38-86 years). Ninety-three patients were Caucasian and the remaining 8 were black. Nine patients had a medical history of systolic hypertension (none of whom were receiving systemic beta blockers) and 2 were diabetic.

Patients were admitted overnight to the hospital for inpatient monitoring of IOP. The first IOP was recorded at 10:00 and thereafter at 2 hourly intervals until 22:00 hours, and finally at 08:00 the next morning. Only those patients who had all eight recordings of IOP during inpatient admission were analysed in this study. IOP was measured by residents or glaucoma technicians using Goldmann applanation tonometry and slit lamp biomicroscopy.

\section{RESULTS}

The diurnal variation in IOP is shown in Table II and Fig. 1. The highest IOP of $17.4 \mathrm{mmHg}$ (SD 3.0) occurred

Table I. Patient selection criteria

1. Intraocular pressure less than $22 \mathrm{mmHg}$ at all clinic visits (patients were, however, allowed to have one IOP reading greater than $21 \mathrm{mmHg}$ but less than $24 \mathrm{mmHg}$ during inpatient phasing)

2. Evidence of glaucomatous cupping and pallor of the optic disc

3. Characteristic and reproducible visual field defects (arcuate, paracentral and nasal scotomas or any combination thereof, with the Humphrey (static). Goldmann (kinetic) or Friedmann (static) perimeter)

4. Corrected visual acuity of $6 / 18$ or better

5. An open angle confirmed by gonioscopy

6. Patients not using systemic or topical beta blockers or corticosteroids

7. Patients not using pressure-lowering therapy

8. No previous laser or filtration surgery

9. No evidence of intracranial pathology on neurological examination 
Table II. Diurnal variation in intraocular pressure (IOP, $\mathrm{mmHg}$ ) in 101 low-tension glaucoma patients

\begin{tabular}{lcc}
\hline Time & Mean IOP & $(\mathrm{SD})$ \\
\hline $08: 00$ & 16.9 & 2.9 \\
$10: 00$ & 17.4 & 3.0 \\
$12: 00$ & 16.5 & 2.8 \\
$14: 00$ & 16.1 & 2.5 \\
$16: 00$ & 15.7 & 2.7 \\
$18: 00$ & 16.0 & 2.5 \\
$20: 00$ & 15.1 & 2.5 \\
$22: 00$ & 15.0 & 2.7 \\
\hline
\end{tabular}

at 10:00 and gradually decreased during the day to reach its lowest value of $15.0 \mathrm{mmHg}(\mathrm{SD} 2.7$ ) at 22:00 hours. The mean peak recording of IOP was 18.3 (SD 2.6) $\mathrm{mmHg}$ and the mean trough IOP was $13.1 \mathrm{mmHg}$ (SD 2.2), giving a mean range of $5.2 \mathrm{mmHg}(\mathrm{SD} 2.2$ ). The overall average recording for all measurements for all patients was $16.1 \mathrm{mmHg}$ (SD 2.6).

Seventy-seven per cent of patients had their peak IOP recorded between 08:00 and 12:00 hours, with 42\% having the peak at 10:00. Sixty-five per cent of patients had their lowest IOP recorded between 18:00 and 22:00 hours, with $31 \%$ of the lowest values occurring at 22:00.

\section{DISCUSSION}

The pathogenesis of optic nerve damage in LTG is not known, although both IOP and vascular risk factors have been postulated. Three recent studies demonstrate that in a sizable proportion of LTG patients with bilateral disease, the eye with the higher mean IOP tended to have greater optic nerve damage and visual field loss. ${ }^{9-11}$ Systemic diseases such as arterial hypertension and diabetes mellitus have been associated with LTG, and recently considerable attention has been given to the possible contributory role of vasospastic disorders such as migraine and Raynaud's phenomenon in LTG. ${ }^{12-14}$

The purpose of this study was to determine whether the pattern and distribution of IOP in LTG contributed to the pathogenesis of neural damage in this disease. Our results are comparable with similar IOP studies in normals where the mean IOP diurnal variation measured by Goldmann applanation tonometry in a study by Kitazawa and Horie ${ }^{5}$ was $6.4 \mathrm{mmHg}$ (SD 1.3). Our results for the mean diurnal IOP range in patients with LTG $-5.2 \mathrm{mmHg}$ (SD 2.2) - almost match that found in normals by David et al. ${ }^{6}$ of $5.0 \mathrm{mmHg}$ (SD 2.7). Thus the diurnal behaviour of IOP in LTG is unlikely to play a prominent role in the aetiology of optic nerve disease in all patients with LTG.

There are very few published data on diurnal IOP in low-tension (or normal-tension) glaucoma. Two recent Japanese studies give a mean diurnal IOP range of $5.5 \mathrm{mmHg}$ (SD 1.6) and $4.8 \mathrm{mmHg}$ (SD 1.8) respectively in LTG. ${ }^{15,16}$ While these values are very similar to our results, the peak and trough IOP in these two reports $-16.5 \mathrm{mmHg}$ and $11.2 \mathrm{mmHg}{ }^{15}$ and $16.5 \mathrm{mmHg}$ and $11.8 \mathrm{mmHg}^{16}$ respectively - are considerably different from our results of $18.3 \mathrm{mmHg}$ and $13.1 \mathrm{mmHg}$ respectively. It is therefore difficult to compare the results

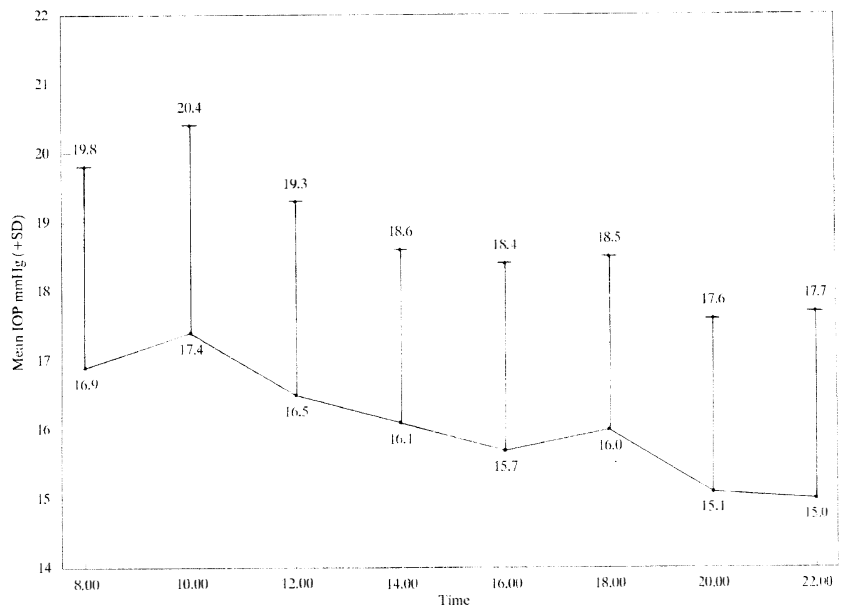

Fig. 1. Diurnal variation in intraocular pressure in low-tension glaucoma.

of the different studies directly. These differences may have arisen because of the different populations studied (Japanese as against mainly Caucasians).

Wilensky ${ }^{17}$ has recently reported that all normals, $78 \%$ of ocular hypertensives and $72 \%$ of glaucoma patients have a diurnal rhythm in IOP curves with a peak pressure recorded either early morning (04:00 to $08: 00)$ or late morning/early afternoon, the majority being late morning. Our data show that for the majority ( $77 \%$ ) of LTG patients, the peak pressure is likely to occur in the morning period between 08:00 and 12:00 hours. This finding confirms recent observations in LTG. ${ }^{15.16}$ The implication is that a single morning measurement will match the diurnal peak in three-quarters of the LTG population: so where facilities are limited, such assessment may substitute for a more comprehensive diurnal IOP evaluation. Diurnal IOP assessment (as described here) will, however, miss peak pressures which may occur between 22:00 and 8:00 hours. Diurnal pressure checks may still be needed as Ido et al.$^{15}$ found that 9 of 100 patients suspected of having LTG and therefore admitted for inpatient IOP monitoring had a peak pressure of more than $21 \mathrm{mmHg}$, causing them to be reclassified as POAG.

We were unable to demonstrate any significant variation in IOP from normal in our study of LTG patients. Yamazaki et al..$^{18}$ have recently shown that LTG patients with a maximum IOP greater than or equal to $19 \mathrm{mmHg}$ had a significantly greater diffuse retinal nerve fibre layer loss than LTG patients with a maximum IOP of less than $19 \mathrm{mmHg}$. Thus further study is required to determine whether different diurnal patterns in IOP are associated with different patterns of optic damage and visual field loss in LTG.

Key words: Diurnal variation, Intraocular pressure, Low tension glaucoma.

\section{REFERENCES}

1. Sidler-Huguenin. Die Späterfolge der Glaukonbehandlung bei 76 privat Patienten van Prof. Dr. Haab, Zurich. Beitr Augenheilkd Hamb a Leipz 1898;32:1-97.

2. Duke-Elder $\mathrm{S}$. The phasic variations in the ocular tension in primary glaucoma. Am J Ophthalmol 1952;35:4-12. 
3. Drance S. The significance of the diurnal tension variations in normal and glaucomatous eyes. Arch Ophthalmol 1960;64:53-4.

4. Katavisto M. The diurnal variation of ocular tension in glaucoma. Acta Ophthalmol (Copenh) Suppl 1964;78:30-80.

5. Kitazawa Y, Horie T. Diurnal variation of intraocular pressure in primary open angle glaucoma. Am J Ophthalmol 1975;79:557-66.

6. David R, Zangwill L, Briscoe D, Dagan M, Yageu R, Yassur Y. Diurnal intraocular pressure variations: an analysis of 690 diurnal curves. Br J Ophthalmol 1992;76:280-3.

7. Sommer A. Intraocular pressure and glaucoma [editorial]. Am J Ophthalmol 1989;107:186-8.

8. Anderson DR. Glaucoma: the damage caused by pressure. Am J Ophthalmol 1989;108:485-95.

9. Cartwright MJ, Anderson DR. Correlation of asymmetric damage with asymmetric intraocular pressure in normaltension glaucoma (low tension glaucoma). Arch Ophthalmol 1988; 106:898-900.

10. Crichton A, Drance SM, Douglas GR, Schulzer M. Unequal intraocular pressure and its relation to asymmetric visual field defects in low tension glaucoma. Ophthalmology 1989;96:1213-4.

11. Haefliger IO, Hichings RA. Relationship between asym- metry of visual field defects and intraocular pressure difference in an untreated normal (low) tension glaucoma population. Acta Ophthalmol (Copenh) 1990;68:564-7.

12. Phelps CD, Corbett JJ. Migraine and low tension glaucoma: a case-control study. Invest Ophthalmol Vis Sci 1988;26:1105-8.

13. Gasser PJ, Flammer J, Guthauser U, Niesel P, Mahler F, Linder HR. Bedeutung des vasospastischen Syndroms in der Augenheilkunde. Klin Monatsbl Augenheilkd 1986; 188:398-9.

14. Schulzer M, Drance SM, Carter CJ, Brooks DE, Douglas SR, Lau W. Biostatistical evidence for two distinct chronic open angle glaucoma populations. $\mathrm{Br} \mathrm{J}$ Ophthalmol 1990;74:196-200.

15. Ido T, Tomita G, Kitazawa Y. Diurnal variation of intraocular pressure of normal tension glaucoma: influence of sleep and arousal. Ophthalmology 1991;98:296-300.

16. Yamagami J, Araie M, Aihara M, Yamamoto S. Diurnal variation in intraocular pressure of normal tension glaucoma eyes. Ophthalmology 1993;100:643-50.

17. Wilensky JT. Diurnal variations in intraocular pressure. Trans Am Ophthalmol Soc 1991;89:758-90.

18. Yamazaki Y, Koide C, Takahashi F, Yomada H. Diffuse nerve fibre layer loss in normal tension glaucoma. Int Ophthalmol 1992;16:247-50. 